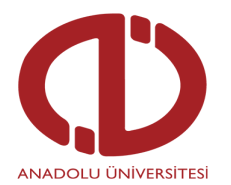

Açıköğretim Uygulamaları ve Araştırmaları Dergisi AUAd

https://dergipark.org.tr/tr/pub/auad

Gönderim: 26.02.2021

Düzeltme: 09.04.2021

Kabul: 15.04 .2021

Tür: Derleme Makale

\title{
Sağlık profesyonellerinin eğitiminde artırılmış gerçeklik uygulamaları
}

\author{
Belgin BOZ YÜKSEKDAĞ $\breve{a}^{\mathrm{a}}$
}

a Anadolu Üniversitesi, Uzaktan Öğretim, ORCID: 0000-0003-2862-3544

\begin{abstract}
Özet
Sağlık profesyonellerinin (doktor, hemşire, ebe vd.) eğitimi, nitelikli sağlık hizmetlerinin sunulmasında kritik bir öneme sahiptir. $\mathrm{Bu}$ mesleklerin adayları kuramsal bilgilerini uygulamaya dönüştürmede bazı zorluklarla karşı karşıyadır. Gerçek uygulama ortamlarının sınırlılı̆̆ı, tıp, hemşirelik ve diğer sağlık alanlarındaki öğrencilerin kliniklerde aynı zamanda staja çımalarının yarattığı yoğunluk, hastaların öğrenciler tarafından bakılmak istememesi, eğitim kurumunda uygulama araçlarının yetersizliği bunlardan bazılarıdır. Öğrenenlerin uygulama ortamlarında etkin ve verimli olması, nitelikli bir öğrenme sürecinin yapılandırılması yeni nesil teknolojilerin öğrenme sürecine dâhil edilmesi ile sağlanabilir. Gerçek dünya ile bağlantısını devam ettiren, veri ve görüntülerin gerçek dünya görüntülerine eklenebildiği, gerçek ve sanal nesnelerin aynı ortamda birlikte algılanmasını sağlayan artırılmış gerçeklik uygulamaları, dünyada ve Türkiye'de birçok alanda kullanılmaktadır. Bu makalede sağlık profesyonellerinin eğitimi açısından artırılmış gerçeklik uygulamaları ele alınarak konuya genel bir bakış sunulmuştur.
\end{abstract}

Anahtar Sözcükler: Artırılmış gerçeklik, sağlık profesyonelleri, eğitim, uygulama.

\section{Augmented reality applications in the education of healthcare professionals}

\begin{abstract}
The education of health professionals (doctor, nurse, midwife, etc.) is critical in providing quality healthcare services. Candidates of these professions face some difficulties in transforming their theoretical knowledge into practice. The limitation of real practice environments, the intensity created by students in medicine, nursing and other health fields going to internships at the same time in clinics, the fact that patients do not want to be cared for by students, the lack of practice tools in the educational institution are some of them. Learners are effective and productive in practice environments and structuring a qualified learning process can be achieved by including new generation technologies in the learning process. Augmented reality applications that maintain their connection with the real world, where data and images can be added to real world images, and enable real and virtual objects to be perceived together in the same environment are used in many areas in the world and in Turkey. In this article, an overview of the subject is presented by considering the applications of augmented reality in terms of education of health professionals.
\end{abstract}

Keywords: Augmented reality, health professionals, education, practice. 


\section{Giriş}

Yirmi birinci yüzyılda insan ve toplum yapısını değiştiren ve dönüştüren büyük teknolojik gelişmeler yaşanmıştır. Bugün de devam eden bu teknolojik gelişmeler belirli alanlarla sınırlı olmamakta, birbirini etkilemekte ve güçlendirmektedir. Mühendislik alanındaki bir gelişmenin tıbba bütünleşebildiği ve tüm disiplinlerin birbirini beslediği bu yeniçağda, eğitim alanında da yeni teknolojiler ve uygulamalar ortaya çıkmıştır. Artırılmış gerçeklik (AG) bu yenilikçi teknolojilerden biridir (Altınpulluk, 2019). Mobil cihazların yaygınlaşması ve giyilebilir teknolojilerin çeşitlenmesi ile farklı boyutlarda şekillenen AG, öğrenme ortamlarının değişmesine neden olmuştur (Altınpulluk ve Kesim, 2015). AG, üç boyutlu ortam ve modellerden oluşan zengin içerikler sağlama, eşzamanlı ve işbirliğine dayalı öğrenme firsatları yaratma, görünmez olanı görünür kılma ve yüksek düzeyde etkileşim sağlama potansiyeline sahiptir. Böylece eğlenceli ve eğitici öğrenme ortamları ile öğrenenlerin öğrenme sürecine etkin katılımı sağlanabilmektedir (Altınpulluk, 2018; Altınpulluk, 2019; Lee, 2012). Bu bağlamda 21. yüzyılda sağlık profesyonellerini yetiştiren eğitim kurumlarının kalite, verimlilik ve sürdürülebilirlik açısından AG teknolojilerini kullanmaları oldukça önemlidir.

Kuramsal ve uygulama aşamalarından oluşan eğitim sürecinde; yazılı-basıl1, görselişitsel öğrenme materyalleri ve öğretim elemanları aracılığı ile oluşturulan kuramsal bilgi birikimi, öğrenenler tarafından kullanıldıkça ve uygulama ortamlarına yansıtıldıkça kalıcı bir öğrenme gerçekleşmektedir (Fotheringham, 2010). Çalışma odağının hasta/sağlıklı bireyler olması nedeniyle tıp, hemşirelik ve diğer sağlık profesyonellerinin eğitim süreçlerinde gerekli becerileri kazanmaları uzun zaman almaktadır. Gerçek uygulama ortamlarına çıkmadan önce bilgi ve beceriler, insan vücuduna ve organlarına benzeyen her türlü model, manken ve kadavralar ya da öğrenenlerin birbirleri üzerinde deneyimlenmektedir. Eğitim süreci ilerledikçe, genellikle deneyimli profesyonellerin gözetiminde gerçek hastalar üzerinde uygulama izni verilmektedir. Bu tür bir uygulamanın, oldukça etkili olmakla birlikte olumsuz yanları da vardır. Uygulama araçlarının yetersizliği, hastalarla pratik yapmanın olası hatalar nedeniyle oldukça riskli olabilmesi, hastaların deneyimsiz doktor, hemşire ve sağlık personelleri tarafından tedavi edilmek ya da bakılmak istememesi, öğrenenlerin invaziv girişimler sırasında yoğun kaygı duymaları uygulamanın zorluklarındandır (Bayar, Çadır ve Bayar, 2009; Erdem ve Sarı, 2018; Wilfong, Falsetti, McKinnon, Daniel ve Wan, 2011). Bu bağlamda, sanal nesnelerin gerçek dünyanın üzerini kapladığı AG, sağlık profesyonellerinin eğitiminde önem kazanmaya başlamıştır (Alaraj, Charbel, Birk, Tobin, Luciano, Banerjee, Rizzi, Sorenson, Foley, Slavin ve Roitberg, 2013; Kamphuis, Barsom, Schijven ve Christoph, 2014; Mitha, Almekhlafi, Janjua, Albuquerque ve McDougall, 2013; Sutherland, Hashtrudi- 
Zaad, Sellens, Abolmaesumi ve Mousavi, 2013; Yudkowsky, Luciano, Banerjee, Schwartz, Alaraj, Lemole, Charbel, Smith, Rizzi, Byrne, Bendok ve Frim, 2013).

\section{Araştırma Sorunsalı}

Sağlık profesyonellerinin (doktor, hemşire, ebe vd.) eğitiminde geleneksel olarak kullanılan uygulama araçları (model, manken, kadavra) ve deneyimli personellerin gözetiminde hasta/sağlıklı birey üzerinde uygulama yapma, etkili bir öğrenme süreci gibi görünse de pek çok riski de beraberinde getirmektedir. Gerek öğrenenler gerekse hasta/sağlıklı bireyler açısından kaygı verici bu durumun ortadan kaldırılması ya da etkisinin en aza indirilmesinde AG uygulamaları, çözüm olabilmektedir (Alaraj vd., 2013; Bayar vd., 2009; Erdem ve Sar1, 2018; Kamphuis vd., 2014; Mitha vd., 2013; Sutherland vd., 2013; Wilfong vd., 2011; Yudkowsky vd., 2013).

AG ile öğrenenler, hastalarının sağlığını riske atma endişesi taşımadan tamamen insan vücuduna ve organlarına benzeyen sanal nesnelerle pratik yapabilmektedir. Kadavralar ya da modeller yerine öğrenenler, insan vücudunu artırılmış gerçeklikte görebilmektedir. AG uygulamaları, insan vücuduna ait parçaları ve organları hareket halinde gösterebildiğinden öğrenenler vücudun işleyişine ilişkin kalıcı öğrenme gerçekleştirebilmektedir (Pınar-Martlı ve Ünlüsoy-Dinçer, 2020; Sarmasoğlu, Dinç ve Elçin, 2016).

$\mathrm{Bu}$ bağlamda eğitim kurumları yeni nesil teknolojilerle paydaşlarını buluşturma noktasında daha istekli olmalıdır. Bu makalede artırılmış gerçeklik teknolojisi ve sağlık alanında özellikle sağlık profesyonellerinin eğitimi konusunda kullanılan bazı artırılmış gerçeklik uygulamaları ele alınmıştır.

\section{Alanyazın}

\section{Artırılmış Gerçeklik}

Artırılmış gerçeklik uygulamaları fiziksel dünyadaki nesne ve mekânların yapay ögeler kullanılarak zenginleştirilmesidir. Başka bir deyişle gerçeklikle etkileşim deneyimini geliştirmek için önemli araçlar sağlayan önemli bir teknolojidir (Altınpulluk, 2015). AG, gerçek hayattaki nesneler yerine dijital nesnelerin kullanıldığı gerçeklik ortamlarıdır (Milgram ve Kishino, 1994). Gerçek ve sanal nesnelerin eş zamanlı olarak etkileşiminin sağlandığı, gerçek dünya ile sanal nesnelerin birleştiği bir teknoloji olan artırılmış gerçeklik (Azuma, 1997; İçten ve Bal, 2017) eğitim, tıp, reklamcılık, savunma, askeri, inşaat ve eğlence gibi farklı alanlarda gelişerek yaygın olarak kullanılmaktadır (Bujak, Radu, Catrambone, MacIntyre, Zheng ve Golubski, 2013; Dunleavy, Dede ve Mitchell, 2009; Klopfer ve Squire, 2007). Masaüstü ve dizüstü bilgisayarlar, taşınabilir cihazlar ile akıllı telefonlar gibi farklı ortamlarda 
da kullanılabilen artırılmış gerçeklik teknolojisi, kullanıcılarına nesnelerle iletişime geçmede farklı cihazları kullanabilme olanağı sunmaktadır (Kirner, Reis ve Kirner, 2012). AG uygulaması, optik temelli ve video temelli teknolojiler olarak iki başlık altında incelenebilir. Optik sistemlerde bütünleştirilmiş sahne, gözlük aracılığıyla gerçek dünyada görülürken, video temelli sistemlerde bütünleştirilmiş sahne, bilgisayar/tablet/mobil cihaz üzerinde görülmektedir (İçten ve Bal 2017). Bir başka deyişle kullanılan teknolojiye bağlı olarak optik ya da video temelli olarak değişmektedir.

AG sistemlerinde üç temel bileşen bulunmaktadır. Bu bileşenler algılayıcılar, işlemciler ve görüntüleyicilerdir (Ekranlar). Algılayıcılar, gerçek dünyaya ilişkin her türlü veriyi (bilgi, konum, sıcaklık, pH, ışık düzeyi) elde ederek, AG uygulamasıyla iletişim kurmaktadır. İşlemcilere kısaca artırılmış gerçeklik sisteminin beyni denilebilir. Görüntüleyiciler ise tüm duyularından algılanan sinyallere aracılık etmektedir. Uygulama, içerik, etkileşim, teknoloji, fiziksel dünya ve katılımcılar, AG’nin içeriğini oluşturmaktadır. AG deneyimlerinin gerçekleştirilebilmesi için hem donanım hem de yazılım gereklidir. Yazılım, sisteme "ne yapılacağını" belirten, donanım ise bunu “yapan” bileşendir (Altınpulluk, 2015).

\section{Sağlık Profesyonellerinin Eğitiminde AG}

Son eğitim teorileri, anlamlı öğrenme için bütünsel beceri eğitimine (Van Merrie"nboer ve Kirschner. 2007) odaklanmaktadır. Bütünsel, gerçekçi ve özgün bir eğitimde "bütün”, karmaşık bilişsel becerilerin giderek daha karmaşık biçimlerinin uygulanmasını ifade etmektedir. "Bütün”, gerçek dünyadaki profesyonel performans için gerekli temel becerilerle birlikte tüm becerinin tam görünümünü ifade etmektedir. Yetkinliklerin sistematik edinimini ve entegrasyonunu teşvik etmek için uygun öğrenme görevleri ve yapı dizileri gereklidir. $\mathrm{Bu}$ bağlamda eğitim teknolojisi, bütünüyle gerçek dünyaya ilişkin eğitim görevlerinin uygulanabileceği güvenli, uygun ve düşük maliyetli bir eğitim ortamı sunma potansiyeline sahiptir. Bu tür kontrollü ortamlarda, öğretim elemanları hastalardan ziyade öğrenenlere odaklanırken, öğrenenler olumsuz sonuçlara neden olmadan hatalar yapabilmektedir. $\mathrm{Bu}$ öğrenme ortamları, öğrenenlere tam zamanında ve yerinde öğrenme firsatları sunmaktadır (Kamphuis vd, 2014).

Sağlık eğitimcileri, AG teknolojisinin, anatomi, fizyoloji gibi zor kuramsal içeriğin öğrenilmesi açısından öğrenenlerin bilgi ve klinik becerilerine, modeller üzerinde öğrenilmesi zor olan sinırlı uygulama alanlarına sahip soyut psikomotor becerilere olumlu katk1 sağlayacağını belirtmektedirler. Ayrıca bu teknolojik gelişmenin mobil cihazlara entegre edilmesiyle daha fazla öğrenenlere ulaşılacağı, öğrenme sürecinin gelişeceği ve öğrenenlerin 
uygulamalar konusunda özgüven kazanacağı belirtilmektedir (Pınar Martlı ve Ünlüsoy Dinçer, 2020).

Sağlık alanında öğrenmenin çoğu uygulama alanı olan hastanelerde gerçekleşmektedir. $\mathrm{Bu}$ ortamlarda öğrenme, bazen çok riskli, organize edilmesi zor ve zaman alıcıdır. Aynı zamanda hastane ortamının karmaşıklığ 1 öğrenenler için genellikle stresli ve kaygı vericidir. $\mathrm{Bu}$ nedenle, mesleki olarak bilgi ve becerilerin kazanılması, yani anlamlı bir öğrenmenin gerçekleşebilmesi için öğrenenlerin, özel bir eğitim ortamında uygun şekilde hazırlanmasını gerektirmektedir. Anlamlı öğrenme, öğrenme transferinin gerçekleşmesi için bir ön şarttır ve aktif, yapıcı, kasıtll, otantik ve işbirliğini gerektirir (Kamphuis vd., 2014). Bir başka deyişle bilgiyi gerçek dünya ile etkileşime girerek, yaparak, yeni yaşantıları var olan bilgi ile bütünleştirerek, hedefe yönelik davranarak, işbirliği ile gerçek uygulama ortamlarında kullanarak anlamlı öğrenme gerçekleştirilebilir.

Artırılmış gerçeklik, anlamlı öğrenme ve öğrenilenlerin aktarımı konusunda güçlü bir potansiyele sahiptir. Fiziksel öğrenme ortamının, profesyonel çalışma ortamı ile aynı değilse de çok benzer olabilmesi, artırılmış (sanal) bölümün, görünmez olanı görselleştirebilmesi, gerçek dünya görevinin dokunsal ve diğer yönlerini simüle edebilmesi, otantik öğrenmeyi destekleyen işbirliği dahil olmak üzere gerekli değişimleri sağlayabilmesi, gerçek zamanlı etkileşimli yapısı, öğrenme süreci üzerinde kontrolü ele almayı destekleyen anında öğrenen geri bildirimi olanağı, öğrenenlerin performansını gözlemlemek için her zaman bir uzman veya öğretim elemanı gerektirmemesi, tam zamanında ve yerinde öğrenmeyi sağlayabilmesi gibi avantajlar sunabilmektedir (Dorward, Mittermeier, Sandbrook ve Spooner, 2016; Kamphuis vd., 2014; Zachary, 2016).

AG sistemlerinin, kullanıcılarının bilişsel katılımını ve fiziksel etkinliklerini artırma potansiyeline sahip olması, eğitim ve özellikle sağlık profesyonellerinin eğitimi konusunda kullanılabilirliğini artırmaktadır (Althoff, White ve Horvitz, 2016; Herron, 2016; LeBlanc ve Chaput, 2016; Nigg, Mateo ve An, 2017; Wagner-Greene, Wotring, Castor, Kruger, Mortemore ve Dake, 2017; Wu, Lee, Chang ve Liang, 2013). Bu bağlamda AG, gerçek dünya ortamına uyarlanabilir, etkileşimli, eğlenceli, heyecan verici, coşkulu ve sürükleyici bir öğrenme ortamı sunarak öğrenmede esneklik sağlar (Barsom, Graafland ve Schijven, 2016; Bujak vd., 2013; Dunleavy, Dede ve Mitchell, 2009).

Sanal nesneler ile gerçek ortamların birlikteliği, öğrenenlerin soyut kavramları ve karmaşık mekânsal ilişkileri anlamalarına yardımcı olmaktadır (Arvanitis, Petrou, Knight, Savas, Sotiriou, Gargalakos ve Gialouri, 2007). Artırılmış gerçeklik, öğrenenlerin yaşadıkları gerçek dünya ile öğrenme ortamlarını birleştirerek öğrenilen bilgi ve becerilerin sorunsuz bir 
şekilde uygulanmasına izin vermektedir. Ayrıca artırılmış gerçekliğin sunduğu gerçek ortamda yüz yüze iletişim kurabilen öğrenenler, grup içerisinde kendi bilgi ve tecrübelerini paylaşabilme imkânına sahip olmaktadır (Lave ve Wenger, 1991).

T1bbi alan, karmaşık öğrenmenin gerçekleştiği bir alandır. Karmaşı öğrenme, karmaşık fizyolojik sistemleri anlamayı, uyarlanabilir uzmanlık geliştirmeyi ve multidisipliner tıp uygulamasında gerekli olan işbirliği becerilerini edinmeyi içermektedir. Bireyin mesleki faaliyetlerini profesyonel ortamda beklenen standartlara göre etkin bir şekilde gerçekleştirmesini sağlayan yetkinliklere sahip olmayı gerektirir. $\mathrm{Bu}$, uzmanlık düzeyine ulaşmak için geniş uygulama firsatı, bağlam ve koşullardaki olası tüm farklılıkları deneyimleme becerisi gerektirmektedir (Kamphuis vd., 2014). Örneğin; karmaşık yapılar içeren kesitsel nöroanatomi gibi bazı konular üç boyutlu görsellerle sunulmalıdır. Beynin anatomik yapısının karmaşık olmasından dolayı öğrenenler nöroanatomi konularında farklı materyallerden bilgi edinmektedir. İki boyutlu atlaslar, kadavra ve magnetik rezonans görüntüleri bu konuda oldukça fazla bilgi vermektedir. Bu yoğun bilgilerin özümsenmesi ve kalıcı öğrenme sağlanabilmesi için öğrenmeyi kolaylaştıran çoklu ortam materyalleriyle desteklenmesi gerekmektedir (Fitzgerald, White, Tang, Maxwell-Armstrong ve James, 2008; Küçük, Kapakin ve Göktaş, 2015; Waterson ve Stewart, 2005).

AG uygulamaları, nesnelerin 3 boyutlu olarak görülebilmesini ve çeşitli perspektiflerden incelenmesini, hata yapma özgürlüğü vererek öğrenenlerin yaparak ve yaşayarak öğrenmelerini ve dolayısıyla hasta güvenliğini sağlamaktadır (Rolland, Davis, Hamza-Lup, Daly, Ha, Martin, Norfleet, Thumann ve Imielinska, 2003; Sielhorst, Obst, Burgkart, Riener ve Navab, 2004; Thomas, John ve Delieu, 2010). Bu özellikle alana özgü becerilerin kazandırılmasında oldukça önemlidir. Örneğin bir tıp ya da hemşire öğrenenin kas içi ya da damar içi enjeksiyonunu gerçekliğin artırıldığı bir ortamda uygulaması, hem öğrenenlerin özgüveni hem de uygulama alanlarında güvenli hasta bakımının sağlanması için gereklidir. Daha kişiselleştirilmiş ve daha özgün öğrenme firsatları ile birden çok öğrenme stiline hitap eden $\mathrm{AG}$, öğrenenlerin üç boyutlu ortamda görsel nesnelerle çalışmasını sağlayarak motivasyon ve öğrenme sürecine aktif olarak katılımını arttırmaktadır (Arvanitis vd., 2007; Ersoy, Duman ve Öncü, 2016; Kerawalla vd., 2006).

AG teknolojisi, sağlık ile ilgili disiplinlerde okuyan öğrenenlere özellikle karar verme, etkili ekip çalışması ve yerel öncelikleri ele almaya yönelik küresel kaynakların uyarlaması gibi temel yetkinliklere ulaşmada da zengin bir öğrenme sağlamaktadır (Frenk, Chen ve Bhutta, 2010; Sherstyuk, Vincent, Berg ve Treskunov, 2011). Örneğin; doktorlar invaziv prosedürlere ihtiyaç duymadan hastanın içsel görünümünü elde edebilmektedir. Bir başka ifadeyle, hastaya 
daha az müdahale ederek, hastayı rahatsız edebilecek uygulamalara gerek kalmadan hasta hakkında bilgi edinebilmektedir (Bajura, Fuchs ve Ohbuchi, 1992; De Paolis, Pulimeno ve Aloisio, 2008; De Paolis, Ricciardi, Dragoni ve Aloisio, 2011; Pandya, Siadat ve Auner, 2005).

\section{AG Teknolojisinin Kullanıldığı Bazı Çalışmalar}

Temel tıp bilimleri ve cerrahi alanlarda yaygın olmak üzere diğer sağlık profesyonellerinin eğitimlerinde de $\mathrm{AG}$ teknolojisinin kullanıldığı görülmektedir. AG teknolojisiyle karmaşık anatomik yapıların öğrenilmesine ilişkin sistemler geliştirilmiştir. Öğrenenler, anatomi öğretimine yönelik AG sistemlerini kullanışlı, kolay, faydalı bulmuşlar ve iyi bir görselleştirme sağladığını belirtmişlerdir (Meng, Fallavollita, Blum, Eck, Sandor, Weidert, Waschke ve Navab, 2013; Thomas, John ve Delieu, 2010; Yeom, Choi-Lundberg, Fluck ve Sale, 2013). Hedeflenen anatomik parçaları yüksek çözünürlükte ve detaylarıyla görüntüleyebilen mobil uygulamaya dayalı bir çalışmada artırılmış gerçeklik ve etkileşim tasarımı, anatomiyi öğretmede bir araç olarak kullanılmıştır. Bu çalışmada önkol ile omuz ekleminin arasında yer alan uzun kol kemiğinin (humerus) AG uygulaması ile görüntüsü oluşturulmuştur (Şekil 1). Çalışma sonucunda AG ile sağlanan görselleştirmenin, anatominin öğretilmesine ve çalışılmasına geleneksel yöntemlerden daha verimli bir şekilde yardımcı olduğu belirtilmiştir (Silva, Klein ve Brandao, 2017).

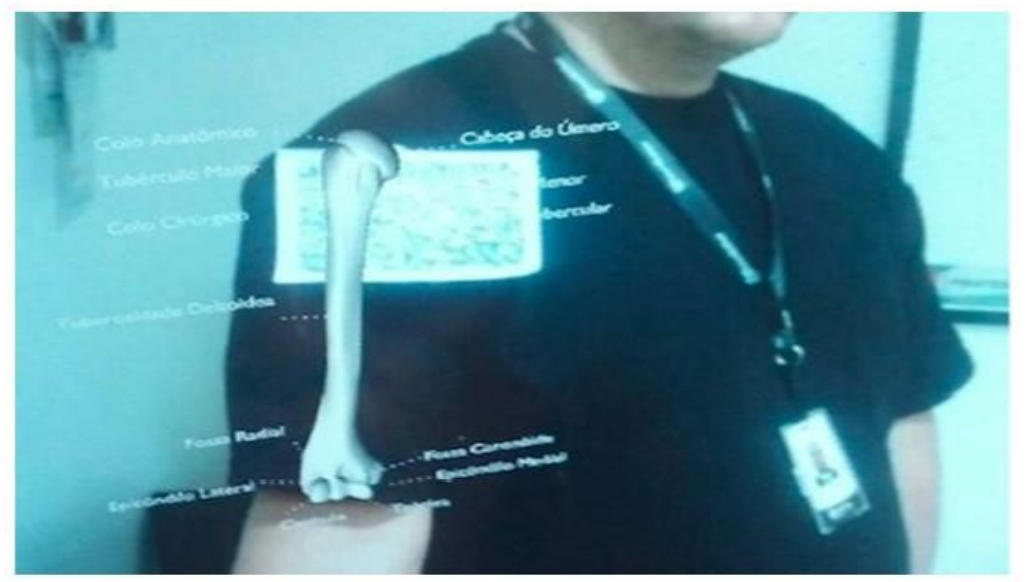

Şekil 1. Gerçek sahnede detaylandırılmış humerus kemiğinin 3B modeli ile AG tarafından oluşturulan görüntüsü (Silva, Klein, Brandao, 2017).

AG teknolojisiyle akciğer anatomisinin görselleştirildiği benzer bir çalışmada öğrenenler, uygulamanın ders kitabına göre çok daha gerçekçi bir görüntü sağladığını ve memnuniyetlerini belirtmişlerdir (Rahn vd., 2014). Anatomi dersinin öğrenilmesinde mobil 
artırılmış gerçekliğin kullanıldığı bir başka çalışmada, öğrenenlerin derse karşı ilgisinin arttığı, anında çevrimiçi kaynaklara erişim sağlandığ 1 ve öğrenenler tarafından esnek bir öğrenme ortamı olarak algılandığ1 belirtilmiştir (Küçük, Kapakin ve Göktaş, 2015). AG ile kalp-akciğer canlandırması eğitiminin gerçekleştirildiği bir çalışmada ise sağlık çalışanlarının çoğu AG ile eğitimi, oyunlaştırma ve daha etkileşimli bir öğrenme deneyimi sağlaması ve görselleştirmelerden dolayı faydalı bulmuşlardır (Balian, McGovern, Abella, Blewer ve Leary, 2019).

AG, cerrahi alanında da oldukça önemlidir. Cerrahide beceri kazanmak, uygulamanın sıklığıyla ilgilidir. Bir cerrahın beceri kazanmak için uygulama yapması ve bu uygulamayı yapabileceği bir hasta bulması oldukça güç ve riskli bir durumdur. Uygulamada kadavraları kullanmak hassas ve ince hareketlerin gelişmesine yardım edebilir, ancak canlı bir vücut üzerinde çalışma durumu gerçekleştirilemediğinden AG ile bunu sağlamak mümkün olabilir. Hareketli görüntüyü bir manken üzerine taşıyarak, canlı bir organizma üzerinde ameliyat yapma izlenimi yaratılabilmektedir. Microsoft Hololens gibi özel kulaklıkların kullanıldığı AG uygulamaları, cerrahlar için iyi bir öğrenme aracı olabilmektedir. Öğrenenler, çeşitli senaryolarla artırılmış gerçeklikte farklı ameliyatları uygulayabilmekte ve sanal hastanın eylemlerine nasıl tepki verdiğini görebilmekte ve bu senaryoları istediği kadar tekrar edebilmektedir (Shuhaiber, 2004).

Botden ve Jakimowicz, (2009), laparoskopik cerrahinin olumsuz sonuçlarını ve hataları önlemek için eğitimin çok önemli olduğunu ve gerçekçi dokunsal geribildirim veren AG uygulamalarının cerrahları laparoskopik beceriler için eğitmede güvenli bir yol olduğunu ifade etmiştir. AG laparoskopik simülatörün sanal gerçeklik (SG) simülatörüne göre en büyük avantajı, stajyerin aynı anda ameliyathanede kullanılan aynı araçları kullanmasına izin vermesidir. Simülatör, sanal gerçeklik sistemlerinde bulunmayan stajyerin çalıştı̆̆ hibrid manken ortamı sayesinde gerçekçi dokunsal geri bildirim sağlamaktadır. Bu simülatör, gerçek nesnelerle etkileşime giren gerçek araçlara dayanan fiziksel olarak gerçekçi bir eğitim ortamı sunmaktadır (Botden ve Jakimowicz, 2009).

Beyin cerrahisinde AG ortamında, bir navigasyon sistemi, beynin anatomik kısmının 3 boyutlu bir görüntüsünü (hacim grafiği) gerçek operasyon alanı üzerine yerleştirebilmektedir. $\mathrm{Bu}$, seyreden cerrah için 3 boyutlu anatomik atlas benzeri etkileşimli bir ortam yaratmaktadır. $\mathrm{Bu}$ nedenle cerrahi navigasyon, dar bir ameliyat alanında cerrahi müdahalenin azaltılması için önemli bir durumdur. Beyin cerrahının avantajına göre, cerrahi anatomi, abdominal organlara göre boşlukta daha sabittir ve uygun kayıt yapılmasına izin vermektedir. AG uygulamasına ilişkin endişeler, diğer cerrahi disiplinlerdekilere benzemektedir. Ameliyat sırasında beyin 
omurilik sıvısı sızıntısı, yerçekimi ve tümörün çıkarılmasının neden olduğu doku hareketinin, kaydı etkileyebileceğidir (Shuhaiber, 2004).

Öte yandan, derinlik algısı, artırılmış gerçeklik tabanlı cerrahi navigasyonda önemli bir sorundur. Mesafe bilgisine sahip bir AG ve SG sisteminin değerlendirilmesine ilişkin bir çalı̧̧mada derinlik algısını iyileştirmek için artırılmış gerçeklikten sanal gerçekliğe sorunsuz bir geçiş uygulanmış, cerrahi aletin ucu ile en yakın organ arasındaki minimum mesafe gerçek zamanlı olarak sağlanmıştır. Artırılmış gerçeklikte derinlik algısının AG ve SG arasında önerilen kesintisiz geçişle iyileştirilebileceği ve minimum mesafenin bir göstergesinin sağlanmasının cerrahi görevleri kolaylaştırdığı belirtilmiştir (Choi, Cho, Masamune, Hashizume ve Hong, 2016).

Savaş alanında önlenebilir ölüm nedenlerini azaltmak için klinik destek aracı olarak AG gözlüklerinin kullanıldığı bir çalışmada $\mathrm{AG}$ gözlüğü kullanan tıp öğrencileri, insan kadavra modellerinde pnömotoraks vakaların kontrol grubundaki öğrencilere göre daha doğru tedavi etmişlerdir. Bu çalışma sonucunda, AG teknolojisinin, deneyimsiz sağlık görevlilerine hızla erişilebilir bilgi sağlayabildiğinden savaş yaralanmalarının tedavisi sırasında gerçek zamanlı olarak kullanılabileceği belirtilmiştir (Wilson, Doswell, Fashola, Debeatham, Darko, Walker, Danner, Matthews ve Weaver, 2013).

Çağdaş hemşirelik eğitiminde yapılandırmacı öğrenme süreci ve bu süreçte aktif rol alan öğrenenler önemlidir. Araştırmalar, öğrenenlerin öğrenmelerinde daha aktif roller üstlenmelerinin hedef nitelikler olan özgüven ve eleştirel düşünme becerilerinin gelişmesinde olumlu sonuçları olduğunu göstermiştir (Houghton, Casey, Shaw ve Murphy, 2014; Jeffries, 2005). Yeni mobil artırılmış gerçeklik teknolojilerinin klinik becerileri kazandırma ve geliştirme potansiyelinin araştırıldığı bir çalışmada, klinik el yıkama, solunum seslerini dinleme, solunumu değerlendirme ve oksijen tedavisi konularında Web tabanlı videolar oluşturulmuştur. Öğrenenler, yatak başında AG kaynaklarına erişimin öğrenmeyi desteklediğini belirtmişlerdir. Öte yandan, çalışmada öğrenme deneyimini olumsuz etkileyen yavaş yükleme, uyumsuz akıllı telefonlar ve internet bağlantısı arızaları gibi teknik sorunlar ve öğretim elemanlarında AG konusunda bilgi eksikliği olduğu belirtilmiştir (Garrett, Jackson ve Wilson, 2015).

Meta2 artırılmış gerçeklik gözlüğünün kullanıldığı bir AG uygulamasında, mesleğe yeni başlayan hemşirelere ve hemşirelik öğrencilerine ameliyat öncesi işlemlerin öğretilmesi ve yapılandırılmış geri bildirim sağlanması amaçlanmıştır. Öğrenenlerin ameliyat öncesi hazırlık aşamalarından sonra işlem sıralarının uygunluğu ile ilgili bireysel geri bildirim aldıkları bu uygulamanın psikomotor becerileri geliştirmek için büyük bir potansiyele sahip olduğu 
belirtilmiştir (Taçgın ve Taçgın, 2020). Hemşirelik eğitimine yenilikçi bir öğretim metodu kazandırmanın ve öğrenenlerin teknoloji ile donatılmasının hedeflendiği bir başka çalışmada ise haptik kontrollü AG teknolojisi kullanılarak gerçeklik hissinin korunduğu, öğrenenlerin nazogastrik tüp yerleştirme becerilerini artırmayı amaçlayan NAZO-AR programı geliştirilmiştir (Şendir ve Kızıl, 2019). AG'in kullanıldığı bir başka çalışmada hemşire öğrenenlerin intravenöz (damar içi) ilaç uygulaması ve kadın mesane kateterizasyonuna ilişkin uygulama beceri düzeyleri incelenmiştir. Öğrenenler, materyali anlama ve beceriyi uygulama konusunda kendilerine güven duyduklarını belirtmişlerdir. Araştırmacılar, AG teknolojisinin hemşirelik eğitiminin temelini oluşturan derslerde, laboratuvar uygulamalarında ve klinik deneyimlerde kullanılmasının hasta bakımında ve klinik becerilerin geliştirilmesinde oldukça önemli olduğunu bildirmiştir (Tilghman, Doswell, Collington, Utili ve Watties-Daniels, 2018).

\section{Sonuçlar}

Sağlık eğitiminde AG uygulamaları ile ilgili araştırma sonuçları, öğrenenlerin AG'i bir öğrenme teknolojisi olarak kabul edebileceklerini göstermektedir. Bu sonuçlara göre AG, tıbbi kavramların anlaşılmasını kolaylaştırmakta ve öğrenmenin kalıcılığını, dolayısıyla öğrenmenin etkisini artırmaktadır. AG teknolojisi ile öğrenme stillerine değinilerek öğrenenlere daha kişisel ve keşifsel bir öğrenme deneyimi sunulmaktadır. Aynı zamanda, AG teknolojisi ile beceri eğitimi sırasında karşılaşılabilecek hatalar, hasta güvenliği için bir risk oluşturmamaktadır (Küçük, Kapakin ve Göktaş, 2015; Zhu, Hadadgar, Masiello ve Zary, 2016).

AG uygulamalarının öğrenenlerin öğrenmeleri üzerinde olumlu sonuçları olduğu gibi, kullanılan teknolojiye bağlı olarak olumsuz sonuçları da bulunmaktadır. AG uygulamaları, öğrenme ortamlarında öğrenenler ve öğretim elemanları için çok sayıda potansiyele sahipken, çoklu ve karışık görevlerde aşırı bilişsel yük, rahatsızlık ve zayıf algılama, zor tasarım ve kullanılabilirlik eksikliği, düşük duyarlı1ık gibi bazı zorluklar olduğu belirtilmiştir. Ancak, iyi tasarlandığında AG, gerçek dünyadaki bağlam farkındalığını güçlendirebilmekte ve öğrenmeyi kolaylaştırabilmektedir (Dunleavy vd., 2009; Wu, Hwang, Yang ve Chen, 2018).

Öğrenme üzerinde önemli etkileri olan artırılmış gerçeklik gibi yenilikçi teknolojiler anlamlı öğrenme ve öğrenilenlerin uygulama ortamlarına aktarımı konusunda güçlü bir potansiyele sahiptir. AG, insan vücudunun nasıl oluştuğuna ve nasıl çalıştığına ilişkin en gerçekçi izlenimi veren gerçeğe benzer sanal nesneler yaratmaktadır. Gerçek hastalar üzerinde uygulamaya kıyasla artırılmış gerçeklikte eğitim, hasta için çok daha az risk içermekte ve böylece öğrenenler çok daha yüksek özgüvene sahip olmaktadır. 


\section{Öneriler}

Türkiye'de sağlık personelini yetiştiren bazı eğitim kurumları öğrenen kontenjanının fazla olması, öğretim elemanının sayıca yetersiz olması, uygulama ve değerlendirme araçlarının çağın gereksinimlerini karşılayamaması nedeniyle nitelikli bir eğitim süreci gerçekleştirememektedir. AG teknolojisini kullanmak oldukça pahalı gibi görünse de örneğin bir anatomi laboratuvarı kurmak, öğrenenlere beceri kazandırmak için örnekler ya da kadavralar bulmak daha maliyetli olabilir. AG uygulamaları ile öğrenenler, gerekli buldukları sıklıkta pratik yapabilirler ve gerekli becerilerin eğitiminde daha iyi sonuçlar sağlayabilirler. Bu bağlamda aşağıdakiler önerilebilir:

- Sağlık eğitimi veren kurumların AG teknolojilerine ilişkin farkındalıklarını artıran çalışmalar yapılabilir.

- AG uygulamalarının sürdürülebilirliği açısından öğretim elemanlarının ve öğrenenlerin yeni nesil teknoloji kullanım düzeylerine ilişkin çalışmalar yapılabilir.

- Türkiye'de yükseköğretime bağl1 pilot bir eğitim kurumu seçilerek AG teknolojisi uygulanabilir.

- Sağlık profesyonellerinin eğitiminde AG teknolojisinin kullanımına ilişkin ulusal ya da uluslararası ortak projeler geliştirilebilir. 


\section{Kaynakça}

Alaraj, A., Charbel, F. T., Birk, D., Tobin, M., Luciano, C., Banerjee, P. P., Rizzi, S., Sorenson, J., Foley, K., Slavin, K. ve Roitberg, B. (2013). Role of cranial and spinal virtual and augmented reality simulation using immersive touch modules in neurosurgical training. Neurosurgery, 72 (1), 115-123.

Althoff, T., White, R. W. ve Horvitz, E. (2016). Influence of pokémon go on physical activity: study and implications. Journal of Medical Internet Research, 18(12),e315. https://doi.org/10.2196/jmir.6759

Altınpulluk, H. (2015). Arttırılmış gerçekliği anlamak: kavramlar ve uygulamalar [Kitap tanıtımı: Understanding augmented reality: concepts and applications by A. B. Craig]. AUAd, 1(4), 123-131.

Altınpulluk, H. (2018). Türkiye'de artırılmış gerçeklikle ilgili hazırlanan tezlerin bibliyometrik analiz yöntemiyle incelenmesi. Ĕgitim Teknolojisi Kuram ve Uygulama, 8 (1), 248-272. https://doi.org/10.17943/etku.337347

Altınpulluk, H. (2019). Determining the trends of using augmented reality in education between 2006-2016. Education and Information Technologies, 24(2), 1089-1114. doi: 10.1007/s10639-018-9806-3

Altınpulluk, H. ve Kesim, M. (2015). Geçmişten günümüze artırılmış gerçeklik uygulamalarında gerçekleşen paradigma değişimleri. Akademik Bilişim, Eskişehir: Anadolu Üniversitesi.

Arvanitis, T. N., Petrou, A., Knight, J. F., Savas, S., Sotiriou, S., Gargalakos, M. ve Gialouri, E. (2007). Human factors and qualitative pedagogical evaluation of a mobile augmented reality system for science education used by learners with physical disabilities. Personal and Ubiquitous Computing, 13(3), 243-250.

Azuma, R. (1997). A survey of augmented reality. Presence: Teleoperators and Virtual Environments, 6(4), 355-385.

Bajura, M., Fuchs, H. ve Ohbuchi, R. (1992). Merging virtual objects with the real world: seeing ultrasound imagery within the patient. $A C M, 26(2), 203-210$. https://doi.org/10.1145/142920.134061

Balian, S., McGovern, S. K., Abella, B. S., Blewer, A. L. ve Leary, M. (2019). Feasibility of an augmented reality cardiopulmonary resuscitation training system for health care providers. Heliyon, 5(8), e02205. https://doi.org/10.1016/j.heliyon.2019.e02205. 
Barsom, E. Z., Graafland, M. ve Schijven, M. P. (2016). Systematic review on the effectiveness of augmented reality applications in medical training. Surgical Endoscopy, 30(10), 41744183. https://doi.org/10.1007/s00464-016-4800-6

Bayar, K., Çadır, G. ve Bayar, B. (2009). Hemşirelik öğrencilerinin klinik uygulamaya yönelik düşünce ve kaygı düzeylerinin belirlenmesi. TAF Preventive Medicine Bulletin, 8(1), 3742.

Botden, S. ve Jakimowicz, J. (2009). What is going on in augmented reality simulation in laparoscopic surgery? Surgical Endoscopy, 23(8), 1693-1700. https://doi.org/10.1007/s00464-008-0144-1

Bujak, K. R., Radu, I., Catrambone, R., MacIntyre, B., Zheng, R. ve Golubski, G. (2013). A psychological perspective on augmented reality in the mathematics classroom. Computers \& Education, 68, 536-544.

Choi, H., Cho, B., Masamune, K., Hashizume, M. ve Hong, J. (2016). An effective visualization technique for depth perception in augmented reality-based surgical navigation. The International Journal of Medical Robotics and Computer Assisted Surgery, 12(1), 62-72. https://doi.org/10.1002/rcs.1657

De Paolis, L. T., Pulimeno, M. ve Aloisio, G. (2008). An Augmented Reality Application for Minimally Invasive Surgery. In: Katashev, A., Dekhtyar, Y., Spigulis, J. (eds) 14th Nordic-Baltic Conference on Biomedical Engineering and Medical Physics. IFMBE Proceedings, vol 20. Springer, Berlin, Heidelberg. https://doi.org/10.1007/978-3-540$\underline{69367-3 \quad 131}$

De Paolis, L.T., Ricciardi, F., Dragoni, A. F., Aloisio, G. (2011) An Augmented Reality Application for the Radio Frequency Ablation of the Liver Tumors. In: Murgante, B., Gervasi, O., Iglesias, A., Taniar, D., Apduhan, B. O. (eds) Computational Science and Its Applications - ICCSA 2011. ICCSA 2011. Lecture Notes in Computer Science, vol 6785. Springer, Berlin, Heidelberg. https://doi.org/10.1007/978-3-642-21898-9 47

Dorward, L. J., Mittermeier, J. C., Sandbrook, C. ve Spooner, F. (2016). Pokémon Go: Benefits, costs, and lessons for the conservation movement. Conservation Letters, 10 (1), 160-165. https://doi.org/10.1111/conl.12326

Dunleavy, M., Dede, C., ve Mitchell, R. (2009). Affordances and limitations of immersive participatory augmented reality simulations for teaching and learning. Journal of Science Education and Technology, 18(1), 7-22. https://doi.org/10.1007/s10956-008-9119-1

Erdem, H. ve Sarı, D. (2018). Sanal gerçeklik devrimi: Hemşirelik eğitiminde değişen teknoloji. Ege Üniversitesi Hemşirelik Fakültesi Dergisi, 34 (1), 109-117. 
Ersoy, H., Duman, E. ve Öncü, S. (2016). Artırılmış gerçeklik ile motivasyon ve başarı: deneysel bir çalışma. Journal of Instructional Technologies \& Teacher Education, 5(1), $39-44$.

Fitzgerald, J. E., White, M. J., Tang, S. W., Maxwell-Armstrong, C. A. ve James, D. K. (2008). Are we teaching sufficient anatomy at medical school? The opinions of newly qualified doctors. Clinical anatomy, 21(7), 718-724. https://doi.org/10.1002/ca.20662

Fotheringham, D. (2010). Triangulation for the assessment of clinical nursing skills: a review of theory, use and methodology. International Journal Of Nursing Studies, 47(3), 386391. https://doi.org/10.1016/j.ijnurstu.2009.09.004

Frenk, J., Chen, L., Bhutta, Z. A., Cohen, J., Crisp, N., Evans, T., .. Z Zurayk, H. (2010). Health professionals for a new century: transforming education to strengthen health systems in an interdependent world. The Lancet (London, England), 376(9756), 1923-1958. https://doi.org/10.1016/S0140-6736(10)61854-5

Garrett, B. M., Jackson, C. ve Wilson, B. (2015). Augmented reality m-learning to enhance nursing skills acquisition in the clinical skills laboratory. Interactive Technology and Smart Education, 12(4), 298-314. https://www.emerald.com/insight/content/doi/10.1108/ITSE-05-2015-0013/full/html

Herron, J. (2016). Augmented reality in medical education and training. Journal of Electronic Resources in Medical Libraries, 13 (2), 51-55.

Houghton, C. E., Casey, D., Shaw, D. ve Murphy, K. (2014). Students' experiences of implementing clinical skills in the real world of practice. Journal of Clinical Nursing, 22 (13/14), 1961-1969. https://doi.org/10.1111/jocn.12014

İçten, T. ve Bal, G. (2017). Artırılmış gerçeklik üzerine son gelişmelerin ve uygulamaların incelenmesi. Gazi Üniversitesi Fen Bilimleri Dergisi Part C: Tasarım ve Teknoloji, 5(2), 111-136. https://dergipark.org.tr/en/download/article-file/840617

Jeffries, P. R. (2005). A framework for designing, implementing and evaluating simulations used as teaching strategies in nursing. Nursing Education Perspectives, 26(2), 96-103.

Kamphuis, C., Barsom, E., Schijven, M. ve Christoph, N. (2014). Augmented reality in medical education? Perspectives on Medical Education, 3(4), 300-311. https://doi.org/10.1007/s40037-013-0107-7

Kerawalla, L., Luckin, R., Seljeflot, S. ve Woolard, A. (2006) "Making it real": Exploring the potential of augmented reality for teaching primary school science. Virtual Reality, 10(34), 163-174. https://doi.org/10.1007/s10055-006-0036-4 
Kirner, T. G., Reis, F. M. V. ve Kirner, C. (2012). Development of an interactive book with Augmented Reality for teaching and learning geometric shapes. In Information Systems and Technologies (CISTI), 7th Iberian Conference on (pp. 1-6).

Klopfer, E. ve Squire, K. (2007). Environmental detectives-the development of an augmented reality platform for environmental simulations. Educational Technology Research and Development, 56(2), 203-228. https://doi.org/10.1007/s11423-007-9037-6

Küçük, S., Kapakin, S. ve Göktaş, Y. (2016). Learning anatomy via mobile augmented reality: Effects on achievement and cognitive load. Anatomical sciences education, 9(5), 411421. https://doi.org/10.1002/ase.1603

Lave, J. ve Wenger, E. (1991). Situated learning: Legitimate peripheral participation. NY: Cambridge University Press.

LeBlanc, A. G. ve Chaput, J. P. (2016). Pokémon Go: A game changer for the physical inactivity crisis? Preventive Medicine. doi: 10.1016/j.ypmed.2016.11.012.

Lee, K. (2012). Augmented reality in education and training. TechTrends, 56(2), 13-21.

Li, H., Gupta, A, Zhang, J. ve Flor, N. (2020). Who will use augmented reality? An integrated approach based on text analytics and field survey. European Journal of Operational Research, 281, 502-516. https://doi.org/10.1016/j.ejor.2018.10.019.

Meng, M., Fallavollita, P., Blum, T., Eck, U., Sandor, C., Weidert, S., Waschke, J. ve Navab, N. (2013). Kinect for interactive AR anatomy learning. IEEE International Symposium on Mixed and Augmented Reality, 277-278.

Milgram, P. ve Kishino, F. (1994). A taxonomy of mixed reality visual displays. IEICE Transactions on Information Systems, 77(12), 1321-1329.

Mitha, A. P., Almekhlafi, M. A., Janjua, M. J., Albuquerque, F. C. ve McDougall, C. G. (2013). Simulation and augmented reality in endovascular neurosurgery: lessons from aviation. Neurosurgery, 72

Suppl 1, $107-114$. https://doi.org/10.1227/NEU.0b013e31827981fd

Nigg, C. R. P., Mateo, D. J. ve An, J. P. (2017). Pokémon GO may increase physical activity and decrease sedentary behaviors regular physical. American Journal of Public Health, 107 (1), 37-38. doi: 10.2105/AJPH.2016.303532.

Pandya, A., Siadat, M. R. ve Auner, G. (2005). Design, implementation and accuracy of a prototype for medical augmented reality. Computer Aided Surgery, 10(1), 23-35. $10.3109 / 10929080500221626$.

Pınar-Martlı, E. ve Ünlüsoy-Dinçer, N. (2020). Hemşirelik eğitiminde teknoloji: artırılmış gerçeklik. Pamukkale Üniversitesi Mühendislik Bilimleri Dergisi. Hemşirelik 
eğitiminde teknoloji: artırılmış gerçeklik. Pamukkale Üniversitesi $\underline{10.5505 / \text { pajes. } 2020.38228}$

Rahn, A. ve Kjaergaard, H.W. (2014). Augmented reality as a visualizing facilitator in nursing education. Proceedings of the INTED 2014 Conference, Valencia, 2014.

Rolland, J., Davis, L., Hamza-Lup, F., Daly, J., Ha, Y., Martin, G., . . Imielinska, C. (2003). Development of a training tool for endotracheal intubation. In: Westwood JD, ed. Medicine meets virtual reality II. IOS Press, 288-294.

Sarmasoğlu, Ş., Dinç, L. ve Elçin, M. (2016). Hemşirelik öğrencilerinin klinik beceri eğitimlerinde kullanılan standart hasta ve maketlere ilişkin görüşleri. Hemşirelikte Ĕgitim ve Araştırma Dergisi, 13(2), 107-115.

Sherstyuk, A., Vincent, D., Berg, B. ve Treskunov, A. (2011). Mixed reality Manikins for Medical Education. In: Berg B, Treskunov A, eds. Handbook of augmented reality. New York: Springer, 479-500. https://doi.org/10.1007/978-1-4614-0064-6_23

Shuhaiber, J. H. (2004). Augmented reality in surgery. Archives of Surgery, 139(2), 170-174. https://doi.org/10.1001/archsurg.139.2.170

Sielhorst, T., Obst, T., Burgkart, R., Riener, R. ve Navab, N. (2004). An augmented reality delivery simulator for medical training. Nature Medicine 7(6), 11-20.

Silva, I.C.S., Klein, G. ve Brandao, D. M. (2017). Segmented and detailed visualization of anatomical structures based on augmented reality for health education and knowledge discovery. Advances in Science, Technology and Engineering Systems Journal, 2(3), 469-478.

Sutherland, C., Hashtrudi-Zaad, K., Sellens, R., Abolmaesumi, P. ve Mousavi, P. (2013). An augmented reality haptic training simulator for spinal needle procedures. IEEE Transactions On Bio-Medical Engineering, 60(11), 3009-3018.

Şendir, M. ve Kızıl, H. (2019). Nazogastrik tüp uygulama öğretiminde yenilikçi bir yaklaşım: NAZO-AR. Düzce Üniversitesi Sağllk Bilimleri Enstitüsü Dergisi, 9(2), 86-90.

Taçgın, Z. ve Taçgın, E. (2020). A smart multimodal augmented reality application skill training for preoperative procedures. Bilişim Teknolojileri Dergisi, 13(1), 57-62.

Thomas, R. G., John, N. W. ve Delieu, J. M. (2010). Augmented reality for anatomical education. Journal of Visual Communication in Medicine, 33(1), 6-15. https://doi.org/10.3109/17453050903557359

Tilghman, J., Doswell, J., Collington, D., Utili, S., Watties-Daniels, S. (2018). Innovative utilization of augmented reality and simulation to promote nursing practice. Annals of Nursing and Primary Care, 1(1). 
Van Merrie“nboer, J. J. G. ve Kirschner, P. A. (2007). Ten steps to complex learning, a systematic approach to four component instructional design. New York: Routledge.

Wagner-Greene, V. R., Wotring, A. J., Castor, T., Kruger, J., Mortemore, S. ve Dake, J. A. (2017). Pokémon GO: Healthy or Harmful?. American Journal Of Public Health, 107(1), 35-36. https://doi.org/10.2105/AJPH.2016.303548

Waterson, S. W. ve Stewart, I. J. (2005). Survey of clinicians' attitudes to the anatomical teaching and knowledge of medical students. Clinical Anatomy, 18(5), 380-384.

Wilfong, D. N., Falsetti, D. J., McKinnon, J. L., Daniel, L. H. ve Wan, Q. C. (2011). The effects of virtual intravenous and patient simulator training compared to the traditional approach of teaching nurses: a research project on peripheral i.v. catheter insertion. Journal of İfusion Nursing, 34(1), 55-62. https://doi.org/10.1097/NAN.0b013e31820219e2

Wilson, K. L., Doswell, J. T., Fashola, O. S., Debeatham, W., Darko, N., Walker, T. M. ve Weaver, W. L. (2013). Using augmented reality as a clinical support tool to assist combat medics in the treatment of tension pneumothoraces. Military Medicine, 178(9), 981-985. https://doi.org/10.7205/MILMED-D-13-00074.

Wu, H. K., Lee, S. W. Y., Chang, H. Y. ve Liang, J. C. (2013). Current status, opportunities and challenges of augmented reality in education. Computers \& Education, 62 (1), 41 49. https://doi.org/10.1016/j.compedu.2012.10.024

Wu, P. H., Hwang, G. J., Yang, M. L. ve Chen, C. H. (2018). Impacts of integrating the repertory grid into an augmented reality-based learning design on students' learning achievements, cognitive load and degree of satisfaction. Interactive Learning Environments, 26(2), 221-234. https://doi.org/10.1080/10494820.2017.1294608

Yeom, S., Choi-Lundberg, D., Fluck, A. ve Sale, A. (2013). User acceptance of a haptic interface for learning anatomy, Proceedings of the IADIS International Conference on eLearning 2013, IADIS Press (International Association for Development of the Information Society), (pp. 239-246). Czech Republic.

Yudkowsky, R., Luciano, C., Banerjee, P., Schwartz, A., Alaraj, A., Lemole, G. M., Jr, . . . Frim, D. (2013). Practice on an augmented reality/haptic simulator and library of virtual brains improves residents' ability to perform a ventriculostomy. Simulation in healthcare :journal of the Society for Simulation in Healthcare,8(1), 25-31. https://doi.org/10.1097/SIH.0b013e3182662c69

Zachary, G. P. (2016). Cognitive enhancement on the (Pokémon) go. IEEE Spectrum, 53 (9). doi: 10.1109/MSPEC.2016.7551334 . 
Zhu, E., Hadadgar, A., Masiello, I. ve Zary, N. (2014). Augmented reality in healthcare education: an integrative review. PeerJ, 2, e469. https://doi.org/10.7717/peerj.469 


\section{Yazarlar Hakkında}

\section{Belgin BOZ YÜKSEKDAĞ}

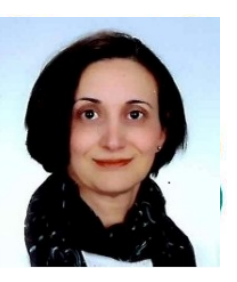

Belgin Boz Yüksekdağ, Anadolu Üniversitesi Açıköğretim Fakültesi Test Araştırma Birimi'nde AR-GE Koordinatörü olarak görev yapmaktadır. Boz Yüksekdağ, Hacettepe Üniversitesi Hemşirelik Yüksekokulu'ndan 1990 y1lında mezun olmuştur. Yazar, 1995 yılında İstanbul Üniversitesi Sağlık Bilimleri Enstitüsü İç Hastalıkları Hemşireliği Ana Bilim Dalı'nda; 2008 y1lında Anadolu Üniversitesi Sosyal Bilimler Enstitüsü Uzaktan Eğitim Anabilim Dalı'nda iki ayrı yüksek lisans derecesine sahiptir. 2013 yılında Marmara Üniversitesi Sağlık Bilimleri Enstitüsü Psikiyatri Hemşireliği Ana Bilim Dalı'nda doktora derecesi kazanan yazar, bilgisayar teknolojilerine dayalı uzaktan hemşirelik eğitimi üzerine çalışmalar yapmaktadır.

Posta adresi: Anadolu Üniversitesi, Açıköğretim Fakültesi, Yunus Emre Kampüsü, Eskişehir, Türkiye.

$\begin{array}{ll}\text { Tel (İss): } & \text { +90 } 2223350580-2701 \\ \text { GSM: } & \text { +90 5545140122 } \\ \text { Eposta: } & \text { bboz@anadolu.edu.tr }\end{array}$

